\title{
Glioma-astrocyte interaction modifies the astrocyte phenotype in a co-culture experimental model
}

\author{
NICOLETTA GAGLIANO $^{1}$, FRANCESCO COSTA ${ }^{1}$, CHIARA COSSETTI $^{2,3}$, \\ LETIZIA PETTINARI ${ }^{1}$, ROSARIA BASSI ${ }^{4}$, MAURIZIO CHIRIVA-INTERNATI ${ }^{5}$, \\ ${\text { EVERARDO } \text { COBOS }^{5} \text {, MAGDA GIOIA }}^{1}$ and STEFANO PLUCHINO ${ }^{2}$
}

\begin{abstract}
${ }^{1}$ Department of Human Morphology and Biomedical Sciences 'Città Studi', Extracellular Matrix Laboratory-EML, School of Medicine, Università di Milano, via F.lli Cervi 93, 20090 Segrate; ${ }^{2}$ CNS Repair Unit, DIBIT2 and Institute of Experimental Neurology (INSPE), Division of Neuroscience, San Raffaele Scientific Institute, via Olgettina 58, 20132

Segrate, Milan, Italy; ${ }^{3} \mathrm{GABB}$ - Graduate Program in Areas of Basic and Applied Biology, Instituto de Ciências Biomedicas Abel Salazar (ICBAS), Universidade do Porto, 4099-002 Porto, Portugal; ${ }^{4}$ Department of Medical Chemistry,

Biochemistry and Biotechnology, L.I.T.A., Università di Milano, via F.lli Cervi 93, 20090 Segrate, Milan, Italy;

${ }^{5}$ Division of Hematology and Oncology, Texas Tech University Health Sciences Center and Southwest Cancer

Treatment and Research Center, 3601 4th St., MS 6591, Lubbock, TX 79430, USA
\end{abstract}

Received July 3, 2009; Accepted August 24, 2009

DOI: $10.3892 /$ or_00000574

\begin{abstract}
As the majority of gliomas arise through malignant transformation of astrocytes, we aimed at investigating the interaction between malignant glioma cells and astrocytes in a co-culture experimental model. For this purpose we analyzed the expression of genes and proteins involved in tumor promotion and invasion, such as glial fibrillary acidic protein (GFAP), matrix metalloproteinase-2 (MMP-2), tissue inhibitor of MMP-2 (TIMP-2), transforming growth factor- 31 (TGF- 31 ), secreted protein acidic and rich in cysteine (SPARC), and connexin 43 (CX43). Co-cultures of human neural stem cell-derived astrocytes and U87 MG astrocytoma cells were performed in a transwell system. Gene expression was evaluated by real-time RT-PCR, and protein analysis was performed by Western blotting, SDS-zymography, and immunofluorescence. GFAP tended to be up-regulated in astrocytes co-cultivated with $\mathrm{U} 87$, suggesting a reactive response induced by glioma cells. CX43 mRNA tended to be down- regulated in co-cultured astrocytes, as well as the nonphosphorylated isoform at the protein level. MMP-2 mRNA tended to be up-regulated, and MMP-2 protein levels were significantly increased in astrocytes co-cultivated with U87. TIMP-2 and SPARC mRNA decreased in astrocytes co-
\end{abstract}

Correspondence to: Dr Nicoletta Gagliano, Department of Human Morphology and Biomedical Sciences 'Città Studi', Extracellular Matrix Laboratory-EML, School of Medicine, University of Milan, Via Fratelli Cervi 93, 20090 Segrate, Milano, Italy

E-mail: nicoletta.gagliano@unimi.it

Key words: glioblastoma, astrocytes, glial fibrillary acidic protein, connexin 43 , matrix metalloproteinase-2, secreted protein acidic and rich in cysteine cultivated with U87, showing lower expression in glioma cells. By contrast, SPARC protein expression was strongly induced in supernatants of co-cultured astrocytes. TGF- $\$ 1$ was not modified. Our results suggest that U87 cells elicit phenotype modifications in the neighbouring resident astrocytes very likely mediated by soluble factors. Glioma/ astrocyte interaction could possibly trigger an astrocyte phenotype modification consistent with a malignant transformation, and favouring a more permissive environment for glioma cells invasion.

\section{Introduction}

Gliomas are the most common primary brain tumors, accounting for $>40 \%$ of all central nervous system neoplasms (1). Malignant gliomas, deriving from neoplastic transformation of astrocytes, are characterized by the aggressive and widespread invasion of glioma cells into surrounding brain tissue (2). The infiltrative potential of gliomas limits the efficacy of surgical resection and targeted radiotherapy, leading to an unfavorable prognosis even in response to multidisciplinary treatment strategies.

Gliomas are 'intraparenchymally metastatic' tumors (3), invading the brain in a non-destructive manner that suggests cooperation between invading glioma cells and their environment, possibly using resident astrocytes as substrate (4).

The mechanism by which glioma cells migrate and invade adjacent normal brain tissue are not yet completely understood, and the behaviour of resident normal astrocytes outside the tumor has not been detailed.

Tumor growth is the result of an evolving cross-talk between malignant and surrounding normal cells. The microenvironment of tumor cells plays a key role in the growth of the tumor, and its modification and remodeling allows tumor invasion, in particular upon up-regulation of matrix metallo- 
proteinase (MMP)-2, as observed in cell lines and resected specimens $(5,6)$.

The previous observation of reactive astrocytes around glioma cells in the brain (7) suggested the possibility that these two cell types could be interacting. In particular, it was hypothesized that this interaction results in exploitation of the astrocyte environment by glioma cells, leading to a remodeling of the surrounding matrix and increased tumor invasiveness.

Although the role of MMP in glioma tumorigenicity is well established, it remains to be determined whether gliomaastrocyte interactions affect other aspects of astrocytes. Normal resident astrocytes and glioma cells interact via gap junctions and growth factors, and the glioma cells could elicit a phenotypic transformation of astrocytes in order to render the brain parenchyma more permissive to glioma invasion.

As the majority of glioma arise through malignant transformation of astrocytes, we aimed at investigating the effect of the interaction between malignant glioma cells and astrocytes in a co-culture experimental model. For this purpose, we focused on astrocytes and we analyzed whether glioma cells triggered any phenotypic change of astrocytes, by analyzing the expression of genes and proteins typical of normal astrocytes and of proteins involved in tumor promotion and invasion.

\section{Materials and methods}

Human neural stem/precursor cell isolation and expansion and differentiation protocol. Human neural stem/precursor cells (hNPCs) were derived from the telencephalon and diencephalon of a single 10.5 post-conception week human foetus, as described (8). Briefly, cells were grown and expanded in a chemically defined, serum-free medium in the presence of basic fibroblast growth factor (FGF)-2 and epidermal growth factor (EGF) (10 and $20 \mathrm{ng} / \mathrm{ml}$, respectively) (growth medium).

To induce differentiation of hNPCs into astrocytes, suspensions of single cells were plated on Matrigel (BD Biosciences) coated 6-well plates $(250,000$ cells/well), in growth medium w/o EGF for the first $72 \mathrm{~h}$. The medium was then replaced with fresh control medium (w/o growth factors) plus $1 \%$ fetal calf serum (FCS). The cells were cultured for further 5 days in vitro before processing for co-culture experiments.

Cell cultures. U87 MG cells were obtained from European Cell Culture Collection and used at the 5th passage for cocultures experiments. Co-cultures of hNPC-derived astrocytes and U87 astrocytoma cells were grown in a transwell system with a $0.4 \mu \mathrm{m}$ pore size. hNPC-derived astrocytes (AA) were seeded in the lower compartment of a 6-well transwell system $\left(2.5 \times 10^{5}\right.$ cells $)$; in the insert U87 $\left(1.25 \times 10^{5}\right.$ or $2.5 \times 10^{5}$ cells) were cultured, or DMEM was placed. Cells were cultured in DMEM supplemented with $10 \%$ heat-inactivated fetal bovine serum (FBS), antibiotics (100 U/ml penicillin, $0.1 \mathrm{mg} / \mathrm{ml}$ streptomycin), and $0.0025 \mu \mathrm{g} / \mathrm{ml}$ ampotericin B. For analysis cells were maintained for $48 \mathrm{~h}$ in serum-free DMEM and then harvested. Each sample was cultured in duplicate, and each co-culture experiment was repeated 3 times.
Immunocytochemistry. AA and U87 were cultured on 12-mm diameter round coverslips put into 24-well culture plates and cultured for $48 \mathrm{~h}$. Cells were washed in phosphate-buffered saline (PBS), fixed in $4 \%$ paraformaldehyde in PBS containing $2 \%$ sucrose for $5 \mathrm{~min}$ at room temperature, and post-fixed in $70 \%$ ethanol and stored at $-20^{\circ} \mathrm{C}$ until use. The cells were then washed in PBS 3 times and incubated overnight at $4^{\circ} \mathrm{C}$ with monoclonal anti-GFAP primary antibody $(1: 800$, Chemicon, Temecula, CA). Secondary antibody conjugated with rodhamine (1:500, Molecular Probes, Invitrogen) was applied for $1 \mathrm{~h}$ at room temperature, followed by rinsing with PBS. Negative controls were incubated omitting the primary antibody. After the labelling procedure was completed, the coverslips were mounted onto glass slides using a mounting medium with DAPI. The cells were photographed by a digital camera connected to the microscope.

Real-time RT-PCR. Total RNA was isolated by a modification of the acid guanidinium thiocyanate-phenol-chloroform method (Tri-Reagent, Sigma). Total RNA $(1 \mu \mathrm{g})$ was reversetranscribed in $20 \mu 1$ final volume of reaction mix (BioRad). The gene expression of MMP-2, TIMP-2, CX43, TGF- 31 and SPARC was analyzed.

The primer sequences, designed with Beacon Designer 6.0 software (BioRad), were: GAPDH: sense CCCTTCATTG ACCTCAACTACATG, antisense TGGGATTTCCATTGA TGACAAGC; MMP-2 sense GCAGTGCAATACCTGA ACACCTTC, antisense TCTGGTCAAGATCACCTGTC TGG; TIMP-2 sense TGGAAACGACATTTATGGCAA CCC, antisense CTCCAACGTCCAGCGAGACC; CX43 sense CTCTCGCCTATGTCTCCTCCTG, antisense TTTGC TCACTTGCTTGCTTGTTG; TGF-ß1: sense GTGCGGCA GTGGTTGAGC, antisense GGTAGTGAACCCGTTGA TGTCC; TIMP-1: sense GGCTTCTGGCATCCTGTTGTTG, antisense AAGGTGGTCTGGTTGACTTCTGG; SPARC: sense GCGAGCTGGATGAGAACAACAC, antisense GTG GCAAAGAAGTGGCAGGAAG.

GAPDH was used as endogenous control to normalize for differences in the amount of total RNA in each sample. Amplification reactions were conducted in a 96-well plate in a final volume of $20 \mu \mathrm{l}$ per well containing $10 \mu \mathrm{l}$ of $1 \mathrm{X}$ SYBR Green Supermix (BioRad), $2 \mu 1$ of template, 300 pmol of each primer, and each sample was analyzed in triplicate. The cycle threshold $(\mathrm{Ct})$ was determined and gene expression levels relative to that of GAPDH were calculated by the $2^{-\Delta \Delta \mathrm{Ct}}$ method.

SDS-zymography. MMP-2 protein levels and activity were assessed by SDS-zymography in cell culture supernatants. Culture media were mixed 3:1 with sample buffer (containing $10 \%$ SDS). Samples (5 $\mu \mathrm{g}$ total protein per sample) were run under non-reducing conditions without heat denaturation onto a $10 \%$ polyacrylamide gel (SDS-PAGE) co-polymerized with $1 \mathrm{mg} / \mathrm{ml}$ of type I gelatin. The gels were run at $4^{\circ} \mathrm{C}$. After SDS-PAGE, the gels were washed twice in $2.5 \%$ Triton X-100 for $30 \mathrm{~min}$ each and incubated overnight in a substrate buffer at $37^{\circ} \mathrm{C}$ (Tris- $\mathrm{HCl} 50 \mathrm{mM}, \mathrm{CaCl}_{2} 5 \mathrm{mM}, \mathrm{NaN}_{3} 0.02 \%, \mathrm{pH} 7.5$ ). The matrix metalloproteinase (MMP) gelatinolytic activity was detected after staining the gels with Coomassie brilliant blue R250, as clear bands on a blue background (9). 
A)

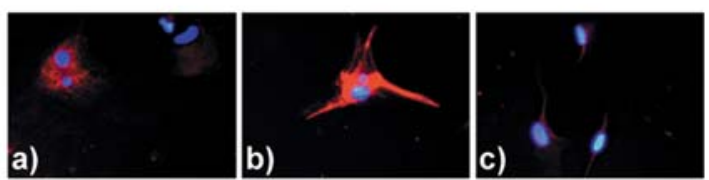

B)

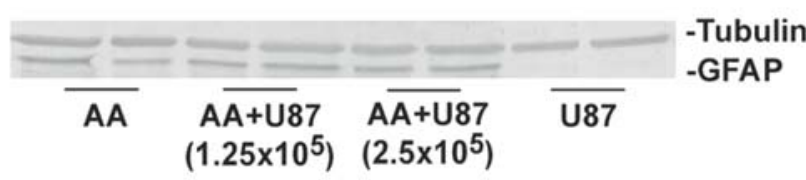

C)

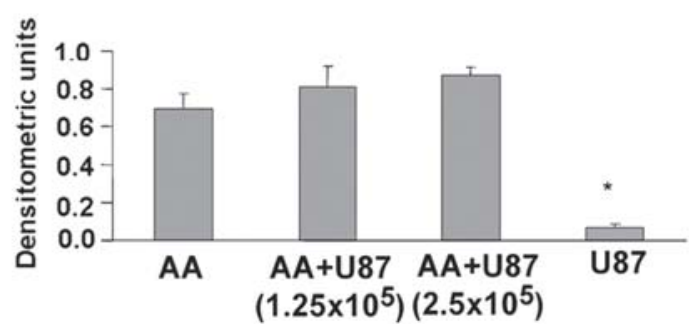

Figure 1. (A) Immunofluorescence analysis of GFAP in AA (a), AA co-cultured with U87 (b), and U87 (c). (B) Representative Western blot analysis for GFAP. (C) Bar graphs showing GFAP protein levels in AA, AA co-cultured with U87, and in U87 glioma cells. Changes in GFAP expression are normalized on tubulin protein levels. Data are reported as densitometric units after scanning of the immunoreactive bands. Values are

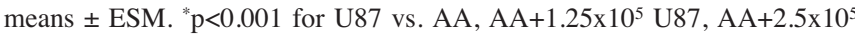
U87.

Western blotting. Cells were lysed in Tris- $\mathrm{HCl} 50 \mathrm{mM}$ pH 7.6, $150 \mathrm{mM} \mathrm{NaCl}, 1 \%$ Triton X-100, $5 \mathrm{mM}$ EDTA, $150 \mathrm{mM}$ $\mathrm{MgCl}_{2}, 1 \% \mathrm{SDS}$, protease inhibitors and $1 \mathrm{mM}$ sodium orthovanadate. Total proteins $(20 \mu \mathrm{g})$ were diluted in SDSsample buffer, loaded on a $10 \%$ SDS-polyacrylamide gel, separated under reducing and denaturing conditions at $80 \mathrm{~V}$, and transferred at $90 \mathrm{~V}$ to a nitrocellulose membrane in $0.025 \mathrm{M}$ Tris, $192 \mathrm{mM}$ glycine, 20\% methanol, pH 8.3. After electroblotting, the membranes were air-dried and blocked for $1 \mathrm{~h}$. After being washed in TBST (TBS/Tween-20, 0.05\%), membranes were incubated for $1 \mathrm{~h}$ at room temperature in monoclonal antibody to GFAP (1:500 in TBST, Santa Cruz Biotechnology, Santa Cruz, CA). After washing, membranes were incubated in HRP-conjugated rabbit anti-mouse serum (1:80,000 dilution in TBST, Sigma). To investigate CX43 protein levels, membranes were reacted with polyclonal anti-CX43 $(2 \mu \mathrm{g} / \mathrm{ml}$ in TBST, Zymed $)$ and HRP-conjugated anti-rabbit serum (1:20000 dilution, Sigma, Milan, Italy). To confirm equal loading, membranes were reprobed by monoclonal antibody to $\alpha$-tubulin (1:2000 dilution, Sigma). Immunoreactive bands were revealed using the Amplified Opti-4CN or the Opti-4CN substrate Bio Rad (BioRad).

SPARC protein levels were assessed in cell culture medium. Total proteins $(25 \mu \mathrm{g})$ were run on $10 \%$ SDS-PAGE gels and electro-blotted as described above. Membranes were incubated in anti-SPARC monoclonal antibody (1:100 in PBST, Novocastra), followed by HRP-conjugated anti-mouse serum (1:6000 dilution, Sigma), and revealed by Opty-4CN substrate. The lysis and immunoreactive bands were analyzed by densitometric scanning (UVBand, Eppendorf).
A)

MMP-2 mRNA levels

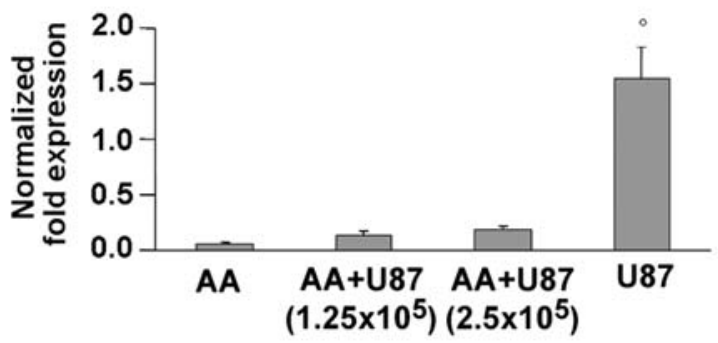

B)

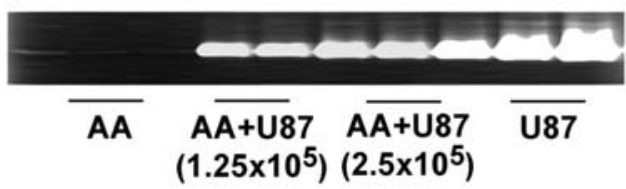

C)

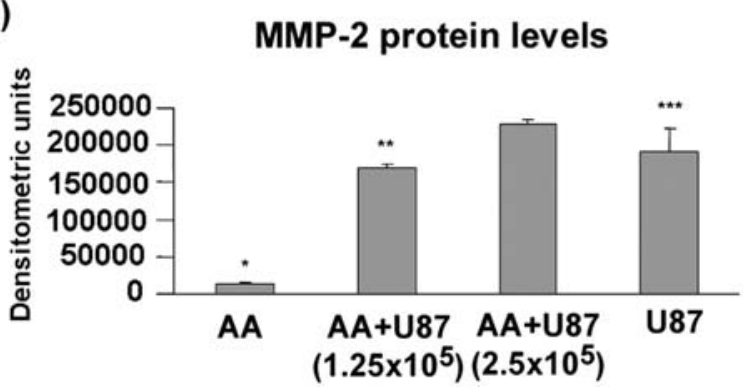

Figure 2. (A) Bar graphs showing MMP-2 mRNA levels in AA, AA co-cultured with U87, and in U87 glioma cells. Changes in mRNA are normalized on GAPDH gene expression. Values are means \pm ESM. (B) Representative gelatin zymogram of MMPs in serum-free conditioned supernatants. The lytic bands correspond to proMMP-2. (C) Bar graphs showing proMMP-2 activity in serum-free conditioned media after densitometric analysis of lytic bands following SDS-zymography. Data are expressed as densitometric units and are means \pm ESM. ${ }^{\circ} \mathrm{p}<0.001$ for U87 vs $\mathrm{AA}+1.25 \times 10^{5} \mathrm{U} 87, \mathrm{AA}+2.5 \times 10^{5} \mathrm{U} 87 .{ }^{*} \mathrm{p}<0.001$ for $\mathrm{AA}$ vs. $\mathrm{AA}+1.25 \times 10^{5}$ $\mathrm{U} 87, \mathrm{AA}+2.5 \times 10^{5} \mathrm{U} 87, \mathrm{U} 87 .{ }^{* *} \mathrm{p}<0.001$ for $\mathrm{AA}+1.25 \times 10^{5} \mathrm{U} 87 \mathrm{vs}$. $\mathrm{AA}+2.5 \times 10^{5} \mathrm{U} 87 .{ }^{* * *} \mathrm{p}<0.05$ for $\mathrm{U} 87 \mathrm{vs} . \mathrm{AA}+2.5 \times 10^{5} \mathrm{U} 87$.

Statistical analysis. All tests were run in duplicate. The GraphPad Prism version 5.0 software package (GraphPad Software) was used for the statistical analysis. Data are expressed as mean \pm standard error (SEM), and were analyzed by one-way analysis of variance (ANOVA) followed by the Student-Neumann-Keuls test. $\mathrm{p}<0.05$ was considered significant.

\section{Results}

GFAP expression. The immunofluorescence analysis revealed that AA co-cultivated with U87 (Fig. 1A, panel b) are strongly positive for GFAP, compared to AA alone (Fig. 1A, panel a), suggesting that glioma/astrocyte interaction induces activation of AA. By contrast, U87 cells (Fig. 1A, panel c) are weakly immunoreactive, confirming a down-regulation of GFAP in malignant gliomas. This finding was confirmed by Western blot analysis (Fig. 1B and C), showing a tendency in GFAP up-regulation in co-cultured AA, compared to AA, and a significant decrease of GFAP immunoreactivity in U87, compared to AA and co-cultured AA ( $\mathrm{p}<0.001$ for U87 vs. $\left.\mathrm{AA}, \mathrm{AA}+1.25 \times 10^{5} \mathrm{U} 87, \mathrm{AA}+2.5 \times 10^{5} \mathrm{U} 87\right)$ 
A)

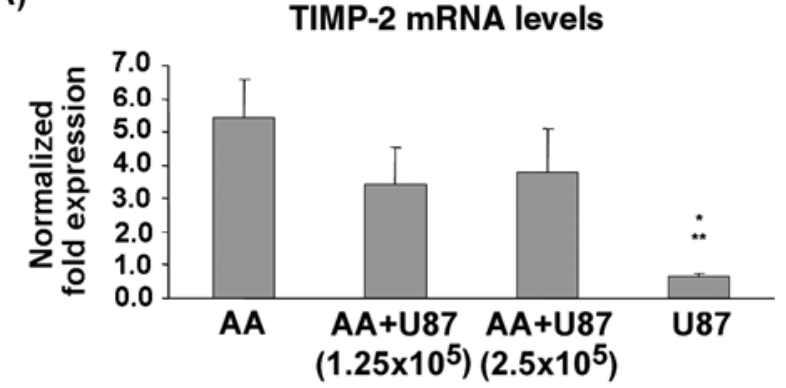

B)

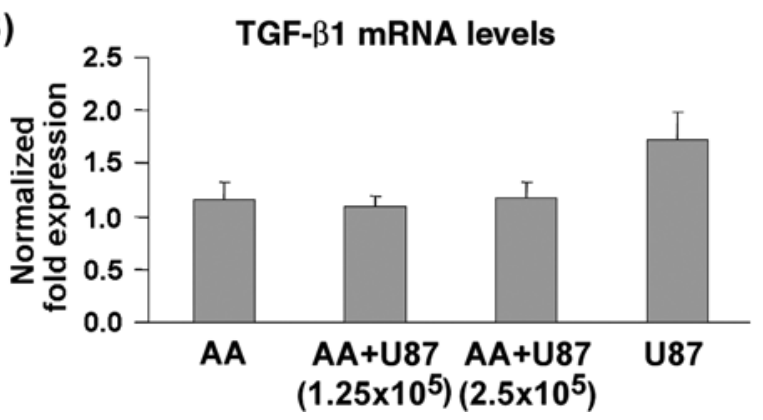

Figure 3. Bar graphs showing TIMP-2 (A) and TGF- $B 1$ (B) mRNA levels in AA, AA co-cultured with U87, and in U87 glioma cells. Changes in mRNA are normalized on GAPDH gene expression. Values are means \pm ESM. ${ }^{*}$ p $<0.01$ for U87 vs. AA. ${ }^{* *} \mathrm{p}<0.05$ for U87 vs. AA+1.25x10 $\mathrm{U} 87$, $\mathrm{AA}+2.5 \times 10^{5} \mathrm{U} 87$.

MMP-2 and TIMP-2 expression. MMP-2 mRNA levels tended to increase in AA co-cultivated with U87, and were highly up-regulated in U87 ( $\mathrm{p}<0.001$ for U87 vs. AA+1.25 $\times 10^{5} \mathrm{U} 87$, $\mathrm{AA}+2.5 \times 10^{5}$ U87) (Fig. 2A). Conversely, SDS-zymography of cell supernatants revealed that the glioma/astrocyte interaction strongly up-regulated MMP-2 at the protein level (Fig. 2B and C). We observed a significant increase of MMP-2 activity in all supernatants from co-cultured AA, compared to AA alone $\left(\mathrm{p}<0.001\right.$ for $\mathrm{AA}$ vs. $\mathrm{AA}+1.25 \times 10^{5}$ $\mathrm{U} 87, \mathrm{AA}+2.5 \times 10^{5} \mathrm{U} 87$ and $\mathrm{U} 87$ ). Interestingly, there is a significant increase of MMP-2 activity in supernatants from co-cultured AA depending on the number of U87 cells seeded in the insert of the transwell system $(p<0.001$ for $\mathrm{AA}+2.5 \times 10^{5} \mathrm{U} 87$ vs. $\left.\mathrm{AA}+1.25 \times 10^{5} \mathrm{U} 87\right)$. The highest activity was evident in U87 supernatants ( $\mathrm{p}<0.05$ for U87 vs. AA). An opposite pattern was evident for TIMP-2 gene expression (Fig. 3A), that slightly tended to decrease in AA co-cultivated with U87, showing the lower expression in U87 $\left(\mathrm{p}<0.001\right.$ for $\mathrm{U} 87 \mathrm{vs.} \mathrm{AA} ; \mathrm{p}<0.05$ for $\mathrm{U} 87$ vs. $\mathrm{AA}+1.25 \times 10^{5}$ $\mathrm{U} 87$ and $\left.\mathrm{AA}+2.5 \times 10^{5} \mathrm{U} 87\right)$.

TGF- $\beta 1$ gene expression. TGF- $\beta 1$ gene expression was similar in AA alone and in co-cultured AA, and tended to be slightly up-regulated in U87 (Fig. 3B).

SPARC gene and protein expression. SPARC gene expression (Fig. 4A) tended to decrease in AA co-cultivated with U87, showing lower expression in glioma cells $(\mathrm{p}<0.001$ for U87 vs. AA; $<<0.05$ for $\mathrm{U} 87$ vs. AA+1.25 $10^{5} \mathrm{U} 87$ and $\left.\mathrm{AA}+2.5 \times 10^{5} \mathrm{U} 87\right)$. SPARC protein levels were similarly expressed in cell lysates obtained from AA, co-cultured AA,
A) SPARC mRNA levels

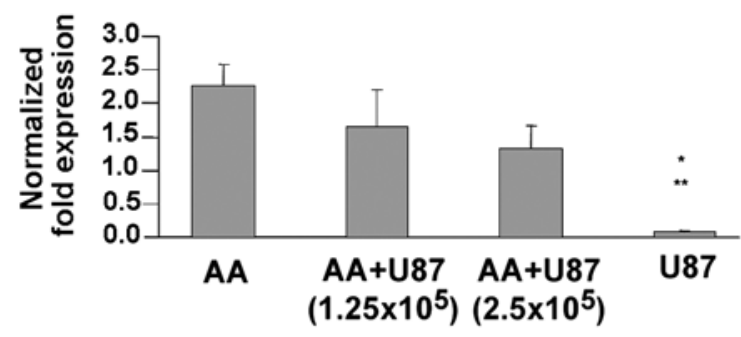

B)

SPARC protein levels in cell lysates

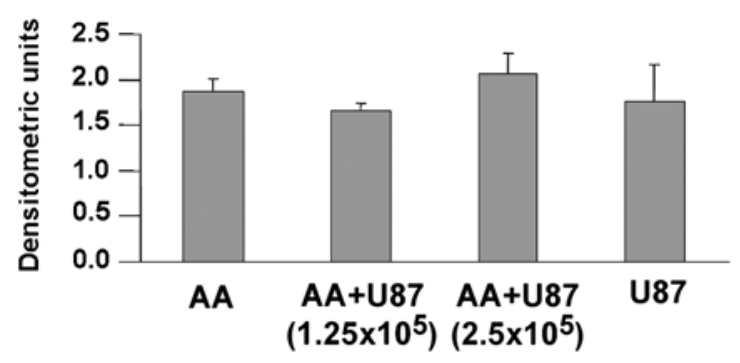

C)

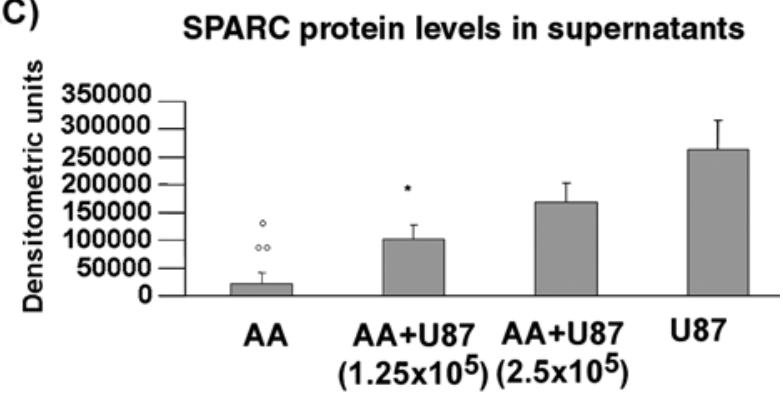

Figure 4. (A) Bar graphs showing SPARC mRNA levels in AA, AA co-cultured with U87, and in U87 glioma cells. Changes in mRNA are normalized on GAPDH gene expression. Values are means \pm ESM. (B) Bar graphs showing SPARC protein levels in cell lysates. Data are reported as densitometric units after scanning of the immunoreactive bands. Values are means \pm ESM. (C) Bar graphs showing SPARC protein levels in cell supernatants. Data are reported as densitometric units after scanning of the immunoreactive bands. Values are means \pm ESM. ${ }^{*} \mathrm{p}<0.001$ vs. AA. ${ }^{* *} \mathrm{p}<0.05$ vs. $\mathrm{AA}+1.25 \times 10^{5} \mathrm{U} 87, \mathrm{AA}+2.5 \times 10^{5}$ U87. ${ }^{\circ} \mathrm{p}<0.001$ vs. U87. ${ }^{\circ} \mathrm{p}<0.01$ vs. $\mathrm{AA}+2.5 \times 10^{5} \mathrm{U} 87 .{ }^{\circ 00} \mathrm{p}<0.05$ for U87 vs. $\mathrm{AA}+1.25 \times 10^{5} \mathrm{U} 87$.

and U87 (Fig. 4B). By contrast, SPARC protein levels in supernatants displayed an opposite pattern. SPARC was almost undetectable in AA alone, but its expression was up-regulated in co-cultured AA and in U87 $(\mathrm{p}<0.001$ for AA vs. U87; $<<0.01$ for $A A$ vs. $A A+2.5 \times 10^{5} \mathrm{U} 87 ; \mathrm{p}<0.05$ for $\mathrm{AA}+1.25 \times 10^{5} \mathrm{U} 87$ vs. U87) (Fig. 4C).

CX43 expression. CX43 expression was evaluated both at the mRNA and at the protein level. Gene expression analysis shows that CX43 tended to be down-regulated in AA cocultured with U87, reaching the lowest expression in U87 glioma cells ( $\mathrm{p}<0.01$ for U87 vs. AA) (Fig. 5A). Western blot analysis demonstrates the pattern of CX43 protein expression (Fig. 5B). Three isoforms of CX43 could be separated on SDS-PAGE and visualized after immunoblotting as three distinct bands: a non-phosphorylated isoform (NP), and the 
A)

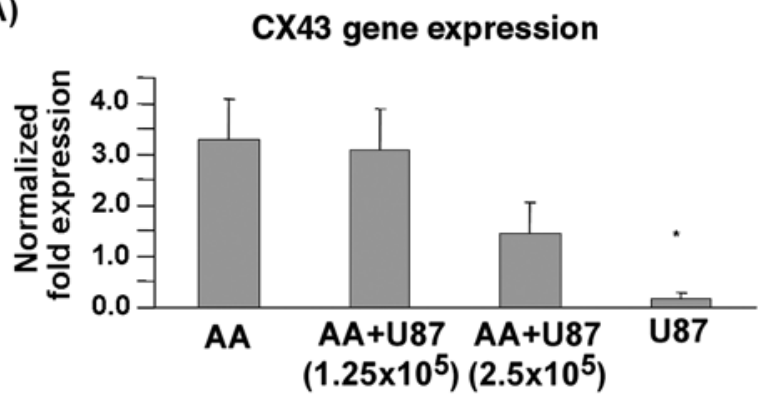

B)

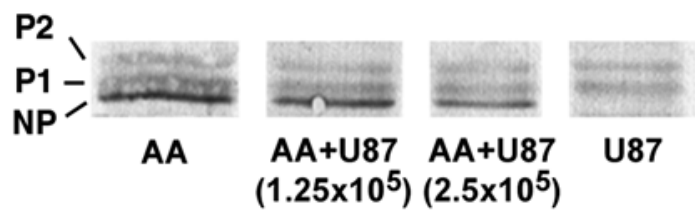

C)

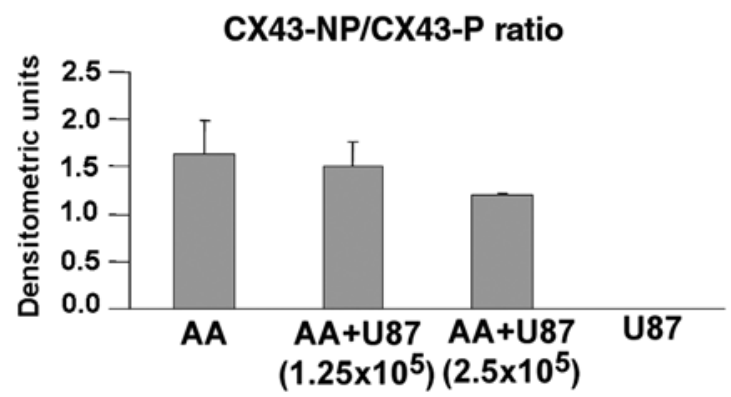

Figure 5. (A) Bar graphs showing CX43 mRNA levels in AA, AA co-cultured with U87, and in U87 glioma cells. Changes in mRNA are normalized on GAPDH gene expression. Values are means \pm ESM. (B) Representative Western blot analysis for CX43. The antibody identifies a lower molecular weight non-phosphorylated isoform (NP), and the two phosphorylated isoforms of the protein (P1 and P2). (C) Bar graphs showing CX43-NP/ CX43-P ratio in AA, AA co-cultured with U87, and in U87 glioma cells Changes in GFAP expression are normalized on tubulin protein levels. Data are reported as densitometric units after scanning of the immunoreactive bands. Values are means $\pm \mathrm{ESM}$. " $\mathrm{p}<0.01$ vs. $\mathrm{AA}+1.25 \times 10^{5} \mathrm{U} 87, \mathrm{AA}+2.5 \times 10^{5}$ U87.

two phosphorylated isoforms of the protein (P1 and P2). CX43-NP isoform (open gap junction) immunoreactivity was high in AA, tended to decrease in co-cultured AA, and was completely undetectable in U87. In the same samples the CX43-P isoform (closed gap junction) tended to increase in co-cultured AA. Interestingly, glioma/astrocyte interaction tended to decrease the CX43-NP/CX43-P ratio in co-cultured AA, compared to AA alone $(\mathrm{p}<0.05$ for U $87 \mathrm{vs}$. AA, $\mathrm{AA}+1.25 \times 10^{5} \mathrm{U} 87, \mathrm{AA}+2.5 \times 10^{5} \mathrm{U} 87$ ) (Fig. $5 \mathrm{~B}$ and $\mathrm{C}$ ), suggesting that $\mathrm{CX} 43$ posttranscriptional phosphorylation influences the open/close status of the gap junction.

\section{Discussion}

Glioblastoma cells are characterized by cellular heterogeneity (10) and, due to their exceptional migratory capacity, they are able to diffusely infiltrate normal brain (11), making total surgical removal impossible; therefore, patients have a poor prognosis, even in response to multidisciplinary treatment strategies including surgery, radiotherapy and chemotherapy
$(12,13)$. Intra-parenchymal invasion of glioma occurs in a non-destructive manner (3), suggesting that glioma cells may establish relationships of cooperation with their environment and in particular with resident brain astrocytes. We focused our attention on the characterization of astrocyte phenotype co-cultured with U87 glioma cells, in order to enlighten how glioma and astrocytes interact, thus providing a possible mechanism of glioma progression.

GFAP is the intermediate filament protein marker of astroglial cells, whose assembly/disassembly status is regulated by phosphorylation, thus affecting cytoskeletal network, cell morphology, motility, differentiation, growth, and mitosis (14). GFAP is also present in astroglial cell nuclei as the major component of the nuclear lamina. With increasing astrocytic malignancy, a progressive loss of GFAP production was reported (15).

In our study, most glioblastoma cells exhibited GFAP immunofluorescence with variations in intensity, and they showed only a diffuse and weak fluorescent signal for GFAP. This is consistent with the previously reported reduced GFAPpositivity in high-grade astrocytomas (16), and a progressive loss of GFAP production described with increasing astocytic malignancy (17). A relationship between increased GFAP protein expression and suppression of glial tumor growth (18), inhibition of cell-cycle progression, and decreased proliferation was previously reported (19).

By contrast, our data show that co-cultured astrocytes tended to overexpress GFAP, compared to astrocytes cultured alone. This evidence suggests that U87 may trigger astrocyte activation and therefore a modification of their phenotype. A strong GFAP immunopositivity was previously reported in vitro (20) and in astrocytes at the periphery around the tumor and, interestingly, these glial cells express primarily MMP-2 and VEGF (21).

Degradation of the ECM in the cell microenvironment is thought to be critical for tumor migration and invasion. MMP-2 is one of the major gelatinolytic MMPs produced in the glioblastomas (22). MMP-2 is the gelatinase mainly involved in extracellular matrix remodeling during tumor invasion, allowing tumor cells to break down basement membranes and diffuse into the surrounding tissues.

Its expression is related to the glioma malignancy grade (23-25), and it was suggested that the modulatory effects of MMP-2 on tumor cell migration could be attributed to both matrix degradation and alterations of adhesion receptors on the cell surface (26), as well as to its involvement in actin mediated motility (27).

The role of TIMP-2, the main inhibitor of MMP-2, is complex. A decrease in overall TIMP-2 expression is reported with increasing grade in gliomas, particularly when measured relative to increasing MMP-2 $(28,29)$.

We observed a significant MMP-2 protein up-regulation in astrocytes co-cultivated with U87, and the concomitant tendency to down-regulation of its inhibitor, TIMP-2, suggesting that U87 could induce a modification of the phenotype of neighboring astrocytes; this phenotype is consistent with a higher ability in remodeling the extracellular matrix of the tumor microenvironment and thus favoring and allowing tumor invasion. At the same time, however, since MMP-2 is reported to be increased in relation to glioma 
malignancy grade, we hypothesize that MMP-2 overexpression induced by U87 in co-cultured astrocytes may be related to a modification of astrocyte phenothype, and that U87 may trigger a malignant transformation of the resident surrounding normal astrocytes.

SPARC is an important multifunctional glycoprotein that influences several biological processes including cellextracellular matrix interaction, and cell differentiation, migration and proliferation. SPARC is highly expressed in human brain tumors $(30,31)$ and in gliomas, regardless of grade, SPARC was highly expressed in the peripheral regions of tumors as well as adjacent to the normal brain tissue (30). Increased SPARC expression correlates with glioma invasion in vitro $(32,33)$ and in vivo $(33-35)$. This is accomplished by up-regulation and activation of MMP-2, and a possible mechanism involved in increased SPARC-dependent ECM degradation via MMP may involve galectin-3 (36). However, the effects of SPARC are complex, and the ability of SPARC to promote invasion depends on the level of its secretion and to the local tumor environment (35). Both low and higher levels of SPARC correlated with more proliferation and promoted a level of ECM adherence conductive for migration in vivo, whilst intermediated levels would promote stronger adherence and less migration. In addition, it was hypothesized that increased glioma invasion would be accompanied by delayed cell growth $(35,37)$. SPARC has a suppressive effect on glioma cell proliferation, delaying cell growth in vitro (37), and delaying tumor growth in rat brains in vivo (35). Intracellular SPARC down-regulation, possibly as a consequence of promoter methylation, was previously reported in human ovarian cancer (38), inducing a delay of cell cycle progression; so the higher level of SPARC is related to the greater percentage of cells in G0/G1 or G2/M phase (37). High levels of SPARC are therefore consistent with a reduced ability to enter the cell cycle and, as a consequence, with a reduced cell proliferation. If cell cycle progression is inhibited by SPARC, it is likely that SPARC functions also in cell differentiation. In fact, SPARC has exhibited prominent expression during the terminal differentiation of cultured human keratinocytes (39), and is believed to regulate terminal differentiation of lens epithelial cells (40).

It was suggested that SPARC may elicit different effects extra- and intracellularly. It is known that SPARC exerts its de-adhesive effects extracellularly through an antagonistic action involving integrin signalling (41). As previously reported (42), SPARC may be translocated in the nucleus after endocytosis, where the protein may exert its effects on the cell cycle.

Our data show that astrocytes express higher levels of SPARC mRNA whilst astrocytes co-cultured with U87 tended to down-regulate SPARC gene expression, suggesting that U87 could interact with astrocytes inducing their proliferation and, possibly, their dedifferentiation, and therefore triggering their malignant transformation. To confirm this hypothesis we also analyzed SPARC protein levels in cell lysates. Our results show that AA, co-cultured AA and U87 display similar intracellular SPARC protein levels, suggesting that the proliferative potential of AA is not affected by U87. By contrast, U87 induced SPARC protein level up-regulation in supernatants of co-cultured astrocytes, suggesting that U87 affect the phenotype of normal resident astrocytes rendering them more able to remodel the tumor micro-environment and more invasive and, very likely, malignant. This hypothesis is consistent with the results of a recent study showing that intracerebral injection of glioma cells transfected with SPARC siRNA in nude mice resulted in the formation of a non-invasive tumor (33).

The comprehension of the very complex mechanisms regulating the different extra- and intracellular SPARC protein levels should be useful in understanding the role of SPARC as a possible target for glioma treatment.

CX43. Gap junctions are ubiquitously expressed by many types of cells, and they are involved in diverse processes related to the regulation of major cell functions including proliferation, differentiation, and cell homeostasis (43-46). CX43 is the most abundant gap junction connexin expressed in astrocytes and glioma cells, and a reduced expression of CX43 has been demonstrated in numerous cancer cells $(47,48)$, including glioma cells. Loss of gap junction coupling has been implicated in malignant transformation: CX43 expression decreases as the grade of glioma/ astrocytoma worsens and an inverse correlation between CX43 expression and tumor malignancy grade exists $(44,49$ 51). Furthermore, forced expression of CX43 has been shown to inhibit proliferation of C6 glioma cells both in vitro and in vivo, suggesting that the CX43 gene can act as a tumor suppressor $(52,53)$. Since gap junctions are closely associated with the control of cell growth (54), growing evidence suggests that CX43 may function as a tumor suppressor gene (44).

CX43 was previously analyzed in direct co-culture experimental models $(4,55)$ and in brain tumor tissues $(51)$, and resulted strongly up-regulated at the margin of tumor invasion as a result of a direct astrocytes-glioma interaction. In our experimental model, we found decreased CX43 gene expression and down-regulation of the non-phosphorylated/ phosphorylated CX43 ratio in co-cultured astrocytes, possibly exerted by soluble factors produced by U87.

Interestingly, CX phosphorylation represents a further mechanism involved in gap junction intercellular communication, since it may favour its internalization and degradation (56). On the basis of our results, we hypothesize that glioma/astrocyte interaction modulates CX43 gene and protein expression, in particular acting on the posttranslational regulation of CX43 by phosphorylation. We observed a decrease of the NP isoform (open gap junction) of CX43. This result suggests that glioma cells influence neighbouring astrocytes very likely modifying their phenotype towards a malignant-like phenotype in which CX43 is downregulated.

The tumor microenvironment is increasingly recognized as shaping tumor phenotypes, including invasiveness, and therefore the assessment of the relative roles of glioma and astrocytes in glioma progression is useful. Considered as a whole, our results suggest that U87 may elicit phenotype modifications of the surrounding resident astrocytes very likely mediated by soluble factors. Our experimental model suggests that glioma/astrocytes interaction could induce astrocyte activation and their phenotype modification. 
On the basis of our results, we can hypothesize that these phenotypic changes may be consistent with a malignant transformation of astrocytes triggered by glioma cells, and/or may render the brain parenchyma permissive to glioma invasion.

Our study contributes to the understanding of the mechanisms that regulate glioma histogenesis and tumorigenesis, and may be useful in the development of new therapeutic strategies to improve the prognosis of patients with incurable gliomas.

\section{Acknowledgements}

C.C. is recipient of a fellowship (SFRH/BD/15899/2005) from the Fundação para a Ciência e a Tecnologia (FCT). This work was supported via the Italian Multiple Sclerosis Foundation (FISM, grants 2004/R/15 to S.P.), the National Multiple Sclerosis Society (NMSS, partial grants RG-4001A1 to S.P.) and Banca Agricola Popolare di Ragusa (BAPR, unrestricted grant to S.P.).

\section{References}

1. Kleihues P, Soylemezoglu F, Schauble B, Scheithauer BW and Burger PC: Histopathology, classification, and grading of gliomas. Glia 15: 211-221, 1995.

2. Schiffer D, Cavalla P, Dutto A and Borsotti L: Cell proliferation and invasion in malignant gliomas. Anticancer Res 17: 61-69, 1997.

3. Bernstein JJ: Local invasion and intraparenchymal metastasis of astrocytomas. Neuropathol Appl Neurobiol 22: 421-424, 1996.

4. Oliveira R, Christov C, Guillamo JS, de Boüard S, Palfi S, Venance L, Tardy $M$ and Peschanski M: Contribution of gap junctional communication between tumor cells and astroglia to the invasion of the brain parenchyma by human glioblastomas. BMC Cell Biol 6: 7, 2005

5. Forsyth PA, Laing TD, Gibson AW, Rewcastle NB, Brasher P, Sutherland G, Johnston RN and Edwards DR: High levels of gelatinase-B and active gelatinase-A in metastatic glioblastoma. J Neurooncol 36: 21-29, 1998.

6. Saxena A, Shriml LM, Dean M and Ali IU: Comparative molecular genetic profiles of anaplastic astrocytomas/ glioblastomas multiforme and their subsequent recurrences. Oncogene 18: 1385-1390, 1999

7. Le DM, Besson A, Fogg DK, Choi KS, Waisman DM, Goodyer CG, Rewcastle B and Yong VW: Exploitation of astrocytes by glioma cells to facilitate invasiveness: a mechanism involving matrix metalloproteinase- 2 and the urokinase-type plasminogen activator-plasmin cascade. J Neurosci 23: 4034-4043, 2003.

8. Vescovi AL, Parati EA, Gritti A Poulin P, Ferrario M, Wanke E, Frölichsthal-Schoeller P, Cova L, Arcellana-Panlilio M, Colombo A and Galli R: Isolation and cloning of multipotential stem cells from the embryonic human CNS and establishment of transplantable human neural stem cell lines by epigenetic stimulation. Exp Neurol 156: 71-83, 1999.

9. Kleiner DE and Stetler-Stevenson WG: Quantitative zymography: detection of picogram quantities of gelatinases. Anal Biochem 218: 325-329,1994.

10. Misra A, Chattopadhyay P, Dinda AK, Sarkar C, Mahapatra AK, Hasnain SE and Sinha S: Extensive intratumor heterogeneity in primary glial tumors as a result of locus non-specific genomic alterations. J Neurooncol 48: 1-12, 2000.

11. Lipinski CA, Tran NL, Bay C, Kloss J, McDonough WS, Beaudry C, Berens ME and Loftus JC: Differential role of proline-rich tyrosine kinase 2 and focal adhesion kinase in determining glioblastoma migration and proliferation. Mol Cancer Res 1: 323-332, 2003.

12. Daumas-Duport C, Scheithauer B, O'Fallon J and Kelly P: Grading of astrocytomas. A simple and reproducible method. Cancer 62: 2152-2165, 1988.
13. Shapiro WR: Current therapy for brain tumors: Arch Neurol 56: 429-432, 1999

14. Inagaki M, Nakamura Y, Takeda M, Nishimura T and Inagaki N: Glial fibrillary acidic protein: dynamic property and regulation by phosphorylation. Brain Pathol 4: 239-243, 1994.

15. Duffy PE, Huang YY and Rapport MM: The relationship of GFAP to cell shape, motility and differentiation of human astrocytoma cells. Exp Cell Res 139: 145-157, 1982.

16. Shiras A, Bhosale A, Shepal V, Shukla R, Baburao VS Prabhakara K and Shastry P: A unique model system for tunor progression in GBM comprising two developed human neuroepithelial cell lines with differential transforming potential and coexpressing neuronal and glial markers. Neoplasia 5: 520-532, 2003.

17. Rutka JT, Murakami M, Dirks PB, Hubbard SL, Becker LE, Fukuyama K, Jung S, Tsugu A and Matsuzawa K: Role of glial filaments in cells and tumors of glial origin: a review. J Neurosurg 87: 420-430, 1997.

18. Toda M, Miura M, Asou, Sugiyama I, Kawase T and Uyemura K: Suppression of glial tumor growth by expression of glial fibrillary acidic protein. Neurochem Res 24: 339-343, 1999.

19. Asklunnd T, Appelskog IB, Ammerpohl O, Ekstrom TJ and Almqvist PM: Histone deacetylase inhibitor 4-phenilbutyrate modulates glial fibrillary acidic protein and connexin 43 expression, and enhances gap-junction communication, in human glioblastoma cells. Eur J Cancer 40: 1073-1081, 2004

20. Lal PG, Ghirnikar RS and Eng LF: Astrocyte-astrocytoma cell line interactions in culture. J Neurosci Res 44: 216-222, 1996.

21. Nagashima G, Suzuki R, Asai J and Fujimoto T: Immunohistochemical analysis of reactive astrocytes around glioblastoma: an immunohistochemical study of postmortem glioblastoma cases. Clin Neurol Neurosurg 104: 125-131, 2002.

22. Rao JS: Molecular mechanisms of glioma invasiveness: the role of proteases. Nat Rev Cancer 3: 489-501, 2003.

23. Nakada M, Nakamura H, Ikeda E, Fujimoto N, Yamashita J, Sato H, Seiki M and Okada Y: Expression and tissue localization of membrane-type 1,2, and 3 matrix metalloproteinases in human astrocytic tumors. Am J Pathol 154: 417-428, 1999.

24. Nakagawa T, Kubota T, Kabuto M, Sato K, Kawano H, Hayakawa T and Okada Y: Production of matrix metalloproteinases and tissue inhibitor of metalloproteinases-1 by human brain tumors. J Neurosurg 81: 69-77,1994.

25. Rao JS, Steck PA, Mohanam S, Stetler-Stevenson WG, Liotta LA and Sawaya R: Elevated levels of M(r) 92,000 type IV collagenase in human brain tumors. Cancer Res 53: 2208-2211, 1993.

26. Deryugina EI, Bourdon MA, Luo GX, Reisfeld RA and Strongin A: Matrix metalloproteinase-2 activation modulates glioma cell migration. J Cell Sci 110: 2473-2482, 1997.

27. Ogier C, Bernard A, Chollet AM, LE Diguardher T, Hanessian S, Charton G, Khrestchatisky $M$ and Rivera S: Matrix metalloproteinase-2 (MMP-2) regulates astrocyte motility in connection with the actin cytoskeleton and integrins. Glia 54: 272-284, 2006.

28. Kachra Z, Beaulieu E, Delbecchi L, Mousseau N, Berthelet F Moumdjian R, Del Maestro R and Béliveau R: Expression of matrix metalloproteinases and their inhibitors in human brain tumors. Clin Exp Metastasis 17: 555-566, 1999.

29. Merzak A, Parker C, Koochekpour S, Sherbet GV and Pilkington GJ: Overexpression of the 18A2/mts1 gene and downregulation of the TIMP-2 gene in invasive human glioma cell lines in vitro. Neuropathol Appl Neurobiol 20: 614-619, 1994.

30. Rempel SA, Golembieski WA, Ge S, Lemke N, Elisevich K, Mikkelsen T and Gutiérrez JA: SPARC: a signal of astrocytic neoplastic transformation and reactive response in human primary and xenograft gliomas. J Neuropathol Exp Neurol 57: 1112-1121, 1998

31. Rempel SA, Ge S and Gutiérrez JA: SPARC: a potential diagnostic marker of invasive meningiomas. Clin Cancer Res 5: 237-241, 1999.

32. Golembieski WA, Ge S, Nelson K, Mikkelsen T and Rempel SA: Increased SPARC expression promotes U87 glioblastoma invasion in vitro. Int J Dev Neurosci 17: 463-472, 1999.

33. Seno $T$, Harada $H$, Kohno $S$, Teraoka M, Inoue A and Ohnishi T: Downregulation of SPARC expression inhibits cell migration and invasion in malignant gliomas. Int J Oncol 34: 707-715, 2009.

34. Rich JN, Shi Q, Hjelmeland M, Cummings TJ, Kuan CT, Bigner DD, Counter CM and Wang XF: Bone-related genes expressed in advanced malignancies induce invasion and metastasis in a genetically defined human cancer model. J Biol Chem 278: 15951-15957, 2003. 
35. Schultz C, Lemke N, Ge S, Golembieski WA and Rempel SA Secreted protein acidic and rich in cysteine promotes glioma invasion and delays tumor growth in vivo. Cancer Res 62: 6270-6277, 2002.

36. McClung HM, Thomas SL, Osenkowski P, Toth M, Menon P, Raz A, Fridman R and Rempel SA: SPARC upregulates MT1MMP expression, MMP-2 activation, and the secretion and cleavage of galectin-3 in U87MG glioma cells. Neurosci Lett 419: 172-177, 2007.

37. Rempel SA, Golembieski WA, Fisher JL, Maile M and Nakeff A: SPARC modulates cell growth, attachment and migration of U87 glioma cells on brain extracellular matrix proteins. J Neurooncol 53: 149-160, 2001.

38. Said N and Motamed K: Absence of host-secreted protein acidic and rich in cysteine (SPARC) augments peritoneal ovarian carcinomatosis. Am J Pathol 167: 1739-1752, 2005.

39. Ford R, Wang G, Jannati P, Adler D, Racanelli P, Higgins PJ and Staiano-Coico L: Modulation of SPARC expression during butyrate-induced terminal differentiation of cultured human keratinocytes: regulation via a TGF-beta-dependent pathway. Exp Cell Res 206: 261-275, 1993.

40. Bassuk JA, Birkebak T, Rothmier JD, Clark JM, Bradshaw A, Muchowski PJ, Howe CC, Clark JI and Sage EH: Disruption of the Sparc locus in mice alters the differentiation of lenticular epithelial cells and leads to cataract formation. Exp Eye Res 68: 321-331, 1999.

41. Motamed K and Sage EH: Regulation of vascular morphogenesis by the matricellular protein SPARC. Kidney Int 51: 1383-1387, 1997.

42. Gooden MD, Vernon RB, Bassuk JA and Sage EH: Cell cycledependent nuclear location of the matricellular protein SPARC: association with the nuclear matrix. J Cell Biochem 74: 152-167, 1999.

43. Goldberg GS, Moreno AP and Lampe PD: Gap junctions between cells expressing connexin 43 or 32 show inverse permselectivity to adenosine and ATP. J Biol Chem 277: 36725-36730, 2002.

44. Huang RP, Hossain MZ, Sehgal A and Boynton AL: Reduced connexin 43 expression in high-grade human brain glioma cells. J Surg Oncol 70: 21-24, 1999.

45. Huang R, Lin Y, Wang CC, Gano J, Lin B, Shi Q, Boynton A, Burke J and Huang RP: Connexin 43 suppresses human glioblastoma cell growth by down-regulation of monocyte chemotactic protein 1 , as discovered using protein array technology. Cancer Res 62: 2806-2812, 2002.
46. Huang RP, Fan Y, Hossain MZ, Peng A, Zeng ZL and Boynton AL: Reversion of the neoplastic phenotype of human glioblastoma cells by connexin 43 (cx43). Cancer Res 58: 5089-5096, 1998.

47. Dermietzel R and Spray DC: Gap junctions in the brain: where, what type, how many and why? Trends Neurosci 16: 186-192, 1993.

48. Yamasaki $\mathrm{H}$ and Naus CC: Role of connexin genes in growth control. Carcinogenesis 17: 1199-1213, 1996.

49. $\mathrm{Pu} \mathrm{P}, \mathrm{Xia} \mathrm{Z}, \mathrm{Yu} \mathrm{S}$ and Huang Q: Altered expression of $\mathrm{Cx} 43$ in astrocytic tumors. Clin Neurol Neurosurg 107: 49-54, 2004

50. Shinoura N, Chen L, Wani MA, Kim YG, Larson JJ, Warnick RE, Simon M, Menon AG, Bi WL and Stambrook PJ: Protein and messenger RNA expression of connexin43 in astrocytomas: implications in brain tumor gene therapy. J Neurosurg 84: 839-845, 1996.

51. Soroceanu L, Manning TJ and Sontheimer H: Reduced expression of connexin-43 and functional gap junction coupling in human gliomas. Glia 33: 107-117, 2001.

52. Omori $\mathrm{Y}$ and Yamasaki H: Mutated connexin43 proteins inhibit rat glioma cell growth suppression mediated by wild-type connexin43 in a dominant-negative manner. Int J Cancer 78 : 446-453, 1998.

53. Zhu D, Kidder GM, Caveney S and Naus CC: Growth retardation in glioma cells cocultured with cells overexpressing a gap junction protein. Proc Natl Acad Sci USA 89: 10218-10221, 1992.

54. Goodenough DA, Goliger JA and Paul DL: Connexins, connexons, and intercellular communication. Ann Rev Biochem 65: 475-502, 1996.

55. Zhang W, Couldwell WT, Simard MF, Song H, Lin JH and Nedergaard M: Direct gap junction communication between malignant glioma cells and astrocytes. Cancer Res 59: 1994-2003, 1999.

56. Laird DW: Connexin phosphorylation as a regulatory event linked to gap junction internalization and degradation. Biochim Biophys Acta 1711: 172-182, 2005. 